\title{
Imprensa regional e políticas da comunicação: situação geral no quadriénio 1999-2002
}

Victor Amaral*

\section{Resumo}

A partir da inegável importância sociocultural da Imprensa Regional, faremos, neste artigo, uma breve incursão sobre as políticas de comunicação para este subsector em Portugal. Nomeadamente, no período do quadriénio 1999-2002 coincidente com a entrada em vigor de um novo regime de incentivos. Esta análise confrontará uma visão proteccionista do Estado, à qual estão “agarrados” grande parte dos cerca de novecentos títulos de imprensa local e regional, e uma visão liberal, que pressupõe novos desafios de inovação e criatividade empresarial. Das quais depende, em grande medida, a sobrevivência e o futuro da imprensa de proximidade.

Palavras-chave: imprensa regional, políticas da comunicação, incentivos, proteccionismo, imprensa de proximidade

\section{Introdução}

Há um interesse crescente pelo mundo da informação regional. É disso exemplo, por um lado, a postura de integração das grandes empresas de comunicação ao adquirirem outras que editam um jornal de difusão regional, como é o caso do Grupo Lusomundo ${ }^{1}$. Por outro lado, assiste-se a uma regionalização e diversificação por parte dos principais jornais de expansão nacional, tal como é prática em vários

\footnotetext{
* Professor de Comunicação e Relações Públicas na Escola Superior de Educação da Guarda/IPG. Prepara a dissertação no âmbito do mestrado em Ciências da Comunicação - Ramo de Especialização em Comunicação, Cidadania e Educação (vicamaral@mail.pt)

${ }^{1}$ Atento aos sinais do mercado, o grupo Lusomundo entrou no sector da Imprensa Regional. No entanto, com uma postura "muito selectiva", como diz o seu presidente, Luís Ribeiro, numa entrevista à revista Meios de Janeiro de 2002. Referia-se, nomeadamente, à "investida" junto do Jornal do Fundão, justificada pelo prestígio, influência, tradição social, política e democrática do título, e, do mesmo modo, no Diário de Notícias da Madeira e Açoriano Oriental, dos mais prestigiados grupos daquelas regiões autónomas [... ] URL: www.aind.pt/meios2002/revjaneiro_2002/luis_ribeiro.html
} 
países europeus, designadamente em Espanha, Alemanha e Itália. ${ }^{2}$ Veja-se o caso do Jornal de Notícias, o Diário de Notícias, o Público e, mais recentemente, o Expresso. Publicações originalmente vocacionadas para as grandes áreas urbanas, com melhor mercado de leitores e anunciantes, apresentam-se agora com estratégias de criação de edições regionalizadas. Naturalmente, não estamos perante uma postura filantrópica dos grandes media para reativamente ao "interior esquecido e ostracizado". Por detrás deste novo localismo informativo não pode estar outra razão que não seja a percepção, com base em indicadores de mercado, de que as regiões são um território de expansão no campo da informação. O objectivo é aumentar a circulação nacional, crescer em termos publicitários, cobrindo e satisfazendo as necessidades de informação a nível local, como parte integrante do produto jornalístico principal. ${ }^{3}$

Perante este posicionamento das grandes empresas jornalísticas, de reforço em vários segmentos editoriais, deve levantar-se uma questão: Serão estas “investidas” capazes de comprometer a força sociocultural da imprensa regional, palco privilegiado de relações sociais de proximidade, promotor de desenvolvimento local, com grande expressão junto das comunidades portuguesas no estrangeiro?

A dúvida leva-nos ao problema que, num quadro limitado de reflexão, procuraremos analisar neste ensaio: a sobrevivência empresarial da Imprensa Regional. Entramos, por isso, num dos aspectos mais críticos, nada consensuais entre poderes políticos, empresariais e associativos, que diz respeito às políticas de comunicação para este subsector desenvolvidas nos últimos anos em Portugal. A uma conclusão prévia podemos chegar: o interesse empresarial dos grandes media pela imprensa regional, ou a lógica dos discursos de proximidade, só vem reforçar a sua real importância. Isto é, ao mesmo tempo que ocorre nas sociedades contemporâneas uma mutação acelerada e globalizante dos processos comunicacionais, os projectos universalistas "batem-se" cada vez mais no campo da informação de proximidade.

Ora, é a partir desta constatação do local como novo "teatro de operações mediáticas" - com o que isso "mexe”, em termos mais globais, ao nível dos critérios de noticiabilidade marcados pela tirania do factor tempo que exige uma ênfase sobre acontecimentos e não sobre problemáticas ${ }^{4}$ - que focamos a importância da imprensa regional. Importância bem expressa no Decreto-Lei 106/88, que lhe define o Estatuto ${ }^{5}$ e que, basicamente, a coloca num patamar de inquestionável valor cívico e democrático.

\footnotetext{
${ }^{2}$ Ver, a este propósito, o artigo "Imprensa nacional aposta em edições regionalizadas", jornal Público, 5 de Março de 2003.

${ }^{3}$ Esta postura dos principais jornais de expansão nacional deverá ter em conta que, fora de Lisboa e Porto, têm menor percentagem de leitores que a imprensa regional (IR). É o que revela, por exemplo, um estudo realizado em 2000, pela Associação Portuguesa de Imprensa (AIND) e o Instituto de Pesquisa de Opinião e Mercado (IPOM), segundo o qual, fora daquelas grandes áreas urbanas, a IR possui cerca de $56 \%$ de leitores, contra $50 \%$ da imprensa nacional. Aqui está uma das razões que justificam a estratégia destes jornais: conquistar quotas de mercado onde, tradicionalmente, os níveis de audiência são baixos, URL: www.aind.pt

${ }^{4}$ Veja-se, a este respeito, um artigo introdutório de Nelson Traquina na antologia Jornalismo: Questões, Teorias e "Estórias", $2^{\mathrm{a}}$ ed., 1999, Comunicação e Linguagem, Lisboa, Vega, pp. 133-141.

${ }^{5}$ Consagrado na Constituição da República Portuguesa o direito à livre expressão, bem como o de informar, de se informar e de ser informado - direito esse regulamentado numa série de diplomas (Lei de Imprensa, Estatuto do Jornalista, Regulamento da Carteira Profissional de Jornalistas e Lei da Alta Autoridade para a Comunicação Social, entre outros) o DL 106/88 sublinha o "papel altamente relevante que a IR desempenha, não só no âmbito regional a que naturalmente
} 
Não podendo aferir a sua verdadeira dimensão, influência e poder, apenas pela quantidade de títulos registados no Instituto de Comunicação Social (cerca de novecentos) a verdade é que, como vimos, trata-se de um sector relevante no cômputo geral da comunicação social nacional. No entanto, fortemente marcado por constrangimentos, decorrentes, em grande medida, das assimetrias regionais que conduzem, também nesta área, a um país a diferentes velocidades. ${ }^{6}$

Partindo desta contextualização, fixemos algumas das questões embrionárias sobre as quais se pretende reflectir. A saber, que atenção merece a imprensa regional por parte do Estado no domínio das políticas de comunicação? Que regime de incentivos? Que opções políticas o justificam? Que reacções do sector? Que perspectivas se divisam no futuro sobre a permanência e desenvolvimento desta imprensa regional e local?

Especificamente, neste ensaio, propomo-nos analisar as políticas de comunicação do Estado Português para este subsector, no período que cobre o último mandato do governo de António Guterres (interrompido com a sua demissão a 17 de Dezembro de 2001, após derrota autárquica do Partido Socialista), correspondente ao quadriénio 1999-2002.

\section{Reformas estruturais}

Em termos gerais, as mais relevantes reformas estruturais no sector das comunicações foram introduzidas durante os governos social-democratas ${ }^{7}$, tendo os governos socialistas conduzido o barco pelas mesmas águas, procurando não se afastar das medidas adoptadas pela União Europeia. Mas, no que se refere à IR, o segundo governo socialista minoritário reformulou, durante o biénio 2000-2001, o sistema de incentivos, com especial atenção aos custos da expedição postal das publicações periódicas, vulgo porte-pago, suportados pelo Estado, que havia sido instituído a partir de 1 de Outubro de 1976.

Tratando-se do mais importante incentivo indirecto do Estado, exclusivamente destinado à imprensa regional, é naturalmente o que tem merecido mais atenção. Quer por parte da administração central, porquanto implica com as contas públicas, quer por parte das associações do sector, que representam os interesses dos associados. Temos, de um lado, a obrigação estatal de apoio, consagrada na Lei e justificada pelos ambientes socioeconómicos desfavoráveis ${ }^{8}$, e, doutro, uma paisagem considerável,

\footnotetext{
mais diz respeito, mas também na informação e contributo para a manutenção de laços de autêntica familiaridade entre gentes locais e as comunidades de emigrantes dispersas pelas partes mais longínquas do mundo(...)”.

${ }^{6}$ Armindo Cachada, num artigo intitulado "A especificidade da imprensa regional e dos correspondentes locais", vaticina que, pese embora a atenção da tutela, "as assimetrias agravam-se e o direito a informar e a ser informado não é igual em todas as regiões (...)",URL:http://inedita.com/GabineteImprensa/cachada.htm

${ }^{7}$ Para uma clarificação das reformas do sistema mediático entre nós, leia-se, de Helena Sousa, o texto "Políticas da comunicação: reformas e continuidades", in A Comunicação e os Media em Portugal (1995-1999) - Cronologia e leitura de tendências, Departamento de Ciências da Comunicação do Instituto de Ciências Sociais da Universidade do Minho, Braga, 2000, pp. 31-51.

${ }^{8}$ Decreto-Lei n. ${ }^{o}$ 56/2001, de 19 de Fevereiro, referente ao último sistema de incentivos do Estado, onde se pode ler que, "sendo a comunicação social indispensável ao exercício dos direitos fundamentais numa sociedade democrática e
} 
logo poderosa, de órgãos de informação regional que dependem, recorrentemente, do dinheiro do Orçamento de Estado (OE). Não admira, portanto, que este seja mais campo de "batalha" do que campo de união. Senão, vejamos, a título de exemplo, o que aconteceu em 1996 - durante o primeiro mandato do Governo de António Guterres (Outubro de 1995 a Outubro de 1999). Nesse ano, o Governo decretou que somente os semanários teriam direito ao porte-pago a $100 \%$, enquanto que outros jornais de periodicidade superior (que, na altura, representavam 60\% dos associados da AIND) teriam que suportar $10 \%$ dos custos nos CTT. Tal decisão governamental motivou críticas por parte da imprensa regional não semanária, por alegada discriminação estatal e, em simultâneo, ausência de posição concertada das cinco associações de imprensa. ${ }^{9}$

Já em Outubro de 2000 (segundo mandato de António Guterres), conhecida a intenção do Governo em alterar o sistema de incentivos, particularmente a reavaliação das condições de acesso ao porte-pago, igualando todos os jornais, o sector voltou a demonstrar discordância. As políticas preconizadas pelo então secretário de Estado da Comunicação Social, Arons de Carvalho, contra o anterior sistema que "fomenta a passividade, o oportunismo, a acomodação, a subsídio-dependência”, ${ }^{10}$ não convenceram as associações. $\mathrm{O}$ anúncio do fim do porte-pago integral caiu mal. Numa iniciativa sem precedentes - por isso mesmo criticada pelos jornais não semanários - as cinco Associações de Imprensa, reunidas em Outubro de 2000, em Fátima (a escolha do local, para além da carga simbólica, demonstra, por outro lado, que muitos dos jornais locais e regionais estão ligados à Igreja), decretaram luto para a imprensa regional, aprovando um slogan de repúdio às novas medidas governamentais. Uma faixa negra foi publicada em muitos jornais locais e regionais do país, com o slogan "Estamos de luto - O Governo quer matar a Imprensa Regional”. ${ }^{11}$

Uma reacção enérgica do sector que pretendia, desta forma, alertar a população para "os efeitos catastróficos" do fim do porte-pago a 100\%, vaticinando, até, que tal medida, de tão impopular, punha em causa a sobrevivência de muitas publicações.

Eis duas faces da mesma moeda. De um lado o mundo da imprensa local e regional, cuja importância social, cultural e política ninguém parece colocar em causa, representada nas negociações quase por tantas vozes como por número de títulos; do outro, um Governo que quer, sobretudo, agradar a todos, correndo o risco de não agradar a ninguém.

Vejamos, a este propósito, as movimentações do sector que antecederam a entrada em vigor do polémico regime de incentivos, cujo conteúdo analisaremos mais adiante.

pluralista, compete por sua vez ao Estado participar no esforço de modernização e profissionalização do sector (...) Esse esforço reveste-se de particular urgência no caso dos órgãos de âmbito local e regional (...)".

${ }^{9}$ A título meramente ilustrativo deste episódio, veja-se a reacção de Nuno Heitor Ferreira, director do quinzenário O Povo do Cartaxo, num artigo de opinião intitulado "Associações decretam luto de quatro anos após morte da Imprensa Regional”, URL: www.aind.pt/meios2000/revnovembro/luto_assoc.html

${ }^{10}$ Cf. Intervenções efectuadas por Arons de Carvalho in www.secs.pt

${ }^{11}$ Consultando os jornais regionais da época, encontra-se ou a faixa ou notícias sobre a iniciativa. Curiosamente, a faixa raramente surge nos jornais regionais mais recentes no mercado e, à vista, com melhor nível profissional. Baseamo-nos, particularmente, nas publicações da Beira Alta e Beira Baixa com edições on-line: Terras da Beira, Nova Guarda, O Interior, Notícias da Covilhã e Jornal do Fundão. 


\section{Novo regime de incentivos: as negociações}

O titular da pasta da Comunicação Social inaugurou uma tipologia negocial descentralizada ao querer reformar o sector, ouvindo, em cada região, quem dele faz parte. Embora a experiência tivesse sido feita já na anterior legislatura, concretamente em 1997, reportamo-nos, apenas, à iniciativa levada a cabo durante o primeiro trimestre de 2000. Num périplo pelo país, que serviu de barómetro sobre o estado do sector, Arons de Carvalho reuniu-se com responsáveis da imprensa local, dando conta da prevista, e confirmada, redução do financiamento do porte-pago, como forma de acabar com situações de concorrência desleal entre imprensa escrita regional. O governante pôde dizer, de viva voz, que muitos jornais não fazem esforço para uma qualificação do seu trabalho, nomeadamente a nível de contratação de profissionais, preocupandose apenas com a tiragem de exemplares de forma a angariarem publicidade e a garantirem o respectivo apoio estatal. ${ }^{12}$

Em Janeiro de 2000, o governante, numa entrevista à revista Meios ${ }^{13}$, concluía que a imprensa regional dá sinais de mudança mas que esta tem sido limitada por um sistema de incentivos que igualiza os jornais em termos de tiragem. Arons defendeu que o Estado pode e deve ter um papel regulador, mas não um papel em que se substitua ao dinamismo dos empresários nem à sua capacidade de iniciativa. Definitivamente defensor de que a relação principal de cada órgão de comunicação social deve ser com os leitores e não com o Orçamento de Estado, Arons de Carvalho dava conta, na referida entrevista, que o porte-pago representa um custo avultado para os cofres públicos. Por exemplo, em 1999 a estimativa apontava para um custo de 3,2 milhões de contos, metade correspondente à expedição para o Estrangeiro e outra metade no Continente.

Em suma, os gastos têm sempre ultrapassado a verba atribuída no OE para este sistema. Razão para que o Governo se tenha obrigado a legislar um corte, ainda que parcial como é o caso. ${ }^{14}$ Embora, noutros contextos, as razões apontadas sejam de outra ordem que não financeira, como por exemplo o facto de Portugal ser o único país da Europa onde se pratica tal política de incentivos exclusivos à imprensa regional.

Mas qual é, de facto, o peso deste sector na definição das políticas para o sector da comunicação social? Antes de qualquer resposta, uma evidência: nenhum governo, até hoje, teve coragem política de mexer além da cosmética conveniente, por mais que reconheça que é preciso implementar mudanças e acompanhar a evolução das políticas similares nos parceiros europeus.

Achámos todavia oportuno, em termos metodológicos, colocar esta questão directamente ao ex-titular da pasta da Comunicação Social. ${ }^{15} \mathrm{Na}$ resposta, Arons de Carvalho explica que, pese embora o regime de incentivos em vigor se destine à comu-

\footnotetext{
${ }^{12}$ Reportamo-nos a notícias publicadas na imprensa local da Guarda, aquando da reunião de Arons de Carvalho com os respectivos responsáveis. Veja-se no semanário Terras da Beira, de 13 de Abril de 2000, uma notícia intitulada "Porte-pago dos jornais regionais deve diminuir". URL:www.terrasdabeira.com

${ }^{13}$ URL:www.aind.pt/meios2000/revjaneiro/arons.html

${ }^{14}$ Idem, ibidem.

${ }^{15}$ Entrevista exclusiva para este ensaio, realizada a 2 de Fevereiro de 2004, via telefone.
} 
nicação social regional - política criticada por alguns sectores detentores de órgãos de comunicação nacionais, como está bem patente num artigo de Paulo Faustino, assessor da administração da Lusomundo Media/PT ${ }^{16}$-, esta “é uma parte menor do esforço estatal no que toca às políticas para o sector em Portugal”. Uma política governamental para a comunicação centraliza-se, recorrentemente, numa parte do sector que é tutelado pelo Governo, como é o caso da RTP, RDP e Lusa ${ }^{17}$. Ou seja, o que diz respeito às empresas privadas, nomeadamente na imprensa regional em geral, "é menos relevante", confirma Arons de Carvalho. Conclui-se, assim, que o sector só é tido em conta por estar instituído um regime de incentivos especificamente para a imprensa local e regional. Tal facto, por si só, "faz com que qualquer governante da área sinta mais preocupação com o que se passa na informação regional do que o que se passa, por exemplo, nas rádios nacionais". ${ }^{18}$

\section{Incentivos institucionais e principais mudanças}

Da estratégia de aproximação à realidade, por um lado, e da convicção política demonstrada pelo então governante, por outro, resultou, na prática, o novo quadro legislativo centrado em três expressões-chave: necessidade de racionalização, moralização e modernização do sector. ${ }^{19}$

Surge então, no biénio 2000-2001, o novo diploma que aboliu a concessão do porte-pago integral, reformulou as condições de acesso ao respectivo apoio e introduziu duas novidades: o incentivo à criação de conteúdos na Internet (ICCI) e o incentivo à iniciativa e desenvolvimento empresarial (IIDE). ${ }^{20}$

Mas as mudanças na concessão do porte-pago foram introduzidas a duas velocidades. A primeira, entre Março de 2001 e Janeiro de 2002, inseriu uma comparticipação estatal máxima de $90 \%$ ou $80 \%$. A segunda é de Janeiro de 2002, data a partir da qual se procedeu à aplicação integral do diploma com uma comparticipação máxima entre $60 \%$ e $80 \%$ para o território nacional e $95 \%$ no envio para o estrangeiro. A lei, que substituía o anterior decreto n. ${ }^{\circ}$ 37/1997 de 31 de Janeiro, prevê uma excepção para

\footnotetext{
${ }^{16}$ Com o título "Lógicas e necessidades de apoio às empresas jornalísticas", o artigo apela a que, tendo em conta a fragilidade das empresas jornalísticas portuguesas e a sua importância estratégica para o desenvolvimento do país e sua afirmação cultural no exterior, "se conceba um programa de apoios mais abrangente e extensível a todos os segmentos da imprensa, onde se inclui a nacional. (...)" URL: www.aind.pt/meios2002/rev_maio/empresas_jornalisticas.html

${ }^{17}$ As três empresas foram sempre a principal dor de cabeça para os sucessivos governos, quer social-democratas quer socialistas. As políticas para o sector nunca foram além de tímidas e "inconsequentes" medidas. Particularmente no caso da RTP que só nos seis anos de governo socialista viu inflacionado o seu passivo de 40 para mais de 140 milhões de contos. É caso, sem dúvida, para se concluir que, à luz destes dados e respectiva conjuntura, "a RTP está condenada à indefinição quanto ao projecto de Serviço Público e à inviabilidade financeira”. (Helena Sousa, op. cit. em 6).

Esta situação anormal da televisão pública é confirmada por Arons de Carvalho, numa entrevista em Março de 2002 à revista Meios, onde assume o fracasso da holding Portugal Global, que pretendia agregar as três empresas, tendo havido, segundo o ex-secretário de Estado, "incoerência do Governo na sua duplicidade em relação à RTP. Por um lado, impelia as administrações a conterem custos (...), por outro, não se eximiu de assinar contratos de concessão que aumentavam os custos. Para além de limitar a angariação de publicidade (...)" URL: www.aind/pt/meios2002/rev_marco/arons_carvalho.html

${ }^{18}$ Entrevista, op. cit. em 13.

${ }^{19}$ Anuário da Comunicação 2002-2003 do Obercom - Observatório da Comunicação, Lisboa, p. 29.

${ }^{20}$ Idem, ibidem.
} 
$15 \%$ dos exemplares expedidos destinados à angariação de novos assinantes, para pessoas com menores recursos, escolas, associações e instituições de solidariedade social. Os critérios de atribuição dos montantes variam em função do número de jornalistas que as empresas candidatas possuem, tiragens, periodicidade e espaço publicitário. ${ }^{21}$ O sistema comporta dupla modalidade de incentivos: indirectos e directos. Os indirectos traduzem-se na figura do porte-pago, que representam os custos de expedição postal suportados pelo Estado. E os directos destinam-se a apoiar o financiamento de projectos que visem intervir nos domínios da a) modernização tecnológica; b) criação de conteúdos na Internet; c) inovação e desenvolvimento empresarial; d)qualificação profissional e outros de interesse relevante na área da comunicação social. ${ }^{22}$

\section{Vitalidade empresarial e dependência do Estado}

Apesar do aumento do valor social da informação local, ${ }^{23}$ referenciada no início deste artigo, o sector vive uma situação complexa, porém em melhoria: a um elevado volume de publicações corresponde um grau de profissionalismo baixo. Esta constatação remete para uma questão central em toda esta problemática; isto é, se os incentivos estatais contribuem para a modernização do sector ou, se pelo contrário, para a sua manutenção deficitária. Por outras palavras, se a qualidade se atinge por injecção de dinheiro do Orçamento de Estado (OE) ou pela vitalidade empresarial independente. Arons refere que, infelizmente, a maioria das associações do sector está muito dependente dos sócios (jornais) que pedem constantes injecções de verbas do OE.

Esta dependência está bem patente num documento enviado ao então secretário de Estado da Comunicação Social, a 20 de Abril de 2000 (no período das negociações do Governo com o sector tendo em vista as alterações legislativas), pelas cinco Associações de Imprensa (AIC, AIND, AIRA, APIR e UNIR) com o título "Critérios-base para atribuição do porte-pago no território nacional" ${ }^{24}$. Num conjunto de seis princípios, o sector em peso defendia que "os critérios de acesso ao porte-pago têm como base a assunção de que a imprensa regional e local presta um relevante serviço público para a coesão nacional, para o fortalecimento da cultura portuguesa, pelo que se justifica a comparticipação do Estado a $100 \%$ em pelo menos uma parte da sua distribuição, e, ainda, que este apoio visa também uma maior profissionalização das empresas editoras (...)".

Pelo mesmo diapasão afinaram mais de 120 jornais, de dezassete distritos portugueses, reunidos a 3 de Maio de 2000, por iniciativa da APIR (a mais representativa

\footnotetext{
${ }^{21}$ Idem, ibidem.

${ }^{22}$ DL n. ${ }^{\circ} 56 / 2001$, de 19 de Fevereiro, Art. $^{\circ} 2$ (Modalidades).

${ }^{23}$ Uma reflexão muito oportuna sobre a actividade jornalística dos meios locais, por Xosé López Garcia, da Universidade de Santiago de Compostela, com o título "Repensar o jornalismo de proximidade para fixar os media locais na sociedade global”, in Comunicação e Sociedade 4, revista editada pelo Núcleo de Estudos de Comunicação e Sociedade da Universidade do Minho, pp. 199-206

${ }^{24}$ URL:www.aind/pt.
} 
do sector), no IV Congresso Nacional de Imprensa Regional, na Cidade de São Vicente (Brasil). Naquela que ficou conhecida como a "Declaração de São Vicente" 25 é referido que, tendo em conta que a IR desempenha um serviço público sendo um dever do Estado estimulá-la e apoiá-la, “impõe-se, assim, a necessidade do pagamento integral do porte-pago, a $100 \%$, para a expedição de jornais regionais tanto dentro do país como para o estrangeiro".

Enquanto o Governo defendia o fim do porte-pago integral, como forma de profissionalizar o sector, este continuava a defender que essa profissionalização depende dos dinheiros do OE.

Face a tal dependência, que facilita a vida dos jornais locais e "aduba" a sua proliferação, quem, sendo "alimentado" pelo sistema, terá interesse em o alterar?

No quadro das negociações anteriores à aprovação do novo regime de incentivos - extensível aos responsáveis dos títulos regionais a quem o governante enviou uma carta $^{26}$-, Arons de Carvalho regista a posição de excepção preconizada pela Associação de Imprensa Não Diária (AIND), ao defender uma visão renovada de aposta no espírito empresarial. O que vinha ao encontro da pretensão estatal. Mas, em altura de eleições para os órgãos sociais internos, "eles tinham medo". No período de preparação do diploma, antes das eleições legislativas de 1999 - que daria o segundo mandato ao Partido Socialista e a António Guterres -, Arons de Carvalho ouviu, entre outras, esta associação que, por ter coincidido com um acto eleitoral interno, assumiu posição oficial a favor do fim do porte-pago a $100 \%$ - como viria a ficar - e posição contrária depois de eleitos os novos órgãos directivos. $\mathrm{O}$ que revela, no essencial, um certo conservadorismo do sector, sendo mais seguro para a boa saúde das empresas jornalísticas locais manterse, pelo menos, o porte-pago: isto é, um apoio do tipo proteccionista do Estado, em vez da adopção de uma concepção liberal, onde predomina a lei da oferta e da procura. ${ }^{27}$

Esta realidade, que nos remete para que papel deve ter o Estado junto da IR, não pode, porém, ser dissociada de um conjunto de factores, internos e externos, que desembocam em constrangimentos raramente ultrapassáveis e que significam uma debilidade congénita de gestão estratégica financeira e de recursos. Entre esses factores, é comum apontar-se, entre outros, a fragilidade empresarial, a fraca taxa de profissionalização, o aumento de custos de edição, o escasso crescimento da difusão e, dependendo de uma conjuntura externa, o mercado publicitário deficitário.

Este cenário, mais acentuado num universo de inúmeras publicações que, servindo-se do apoio estatal, nem sequer chegam às bancas, faz com que estejamos perante um campo específico, com vasta diversidade de "culturas" e lógicas muito particulares de sobrevivência às adversidades, que remete para a complexidade do processo comunicativo regional em Portugal, merecedor de nova e ampla reflexão. ${ }^{28}$

\footnotetext{
${ }^{25}$ URL:www.aind/pt/meios2000/revjunho/apir.html

${ }^{26}$ Em Outubro de 2000, meses antes da entrada em vigor da nova lei, Arons escreve aos directores dos jornais regionais o seguinte: "Estamos certos de que esta alteração não irá afectar os órgãos de Imprensa Regional que dispõem de uma rede efectiva de assinantes, que pagam regularmente, penalizando, isso sim, os que sempre usaram o porte-pago para enviar gratuitamente milhares de exemplares, à custa do dinheiro dos contribuintes". URL: www.aind.pt/meios2002/ ver_fevereiro/imprensa_regional.html
} 


\section{Fragilidades e incentivos institucionais (1999-2002)}

Abordada uma perspectiva qualitativa da IR, fixemo-nos, numa breve referência quantitativa, nos indicadores económicos divulgados pelo Observatório da Comunicação (Obercom $)^{29}$ e que demonstram, precisamente, um sector fragilizado. Representando apenas 5\% do mercado publicitário - um dos constrangimentos de que falávamos -, o sector da imprensa regional viu diminuídas as receitas desde 1999, ano de crise generalizada pelo abrandamento económico, com uma quebra de $7,5 \%$ no ano 2000, que se traduziu numa descida dos 7,2 para os 6,7 milhões de contos. Por seu lado, o volume de negócios, entre 99 e 2000, decaiu de 63,35 milhões de euros (12,7 milhões de contos) para 53,87 milhões de euros (10,8 milhões de contos), uma quebra na ordem dos $15 \%$.

Segundo o Obercom, a tendência decrescente no segmento da imprensa regional vem-se acentuando desde meados de 2000, estimando-se que em 2001, ano da entrada em vigor do novo regime de incentivos, o decréscimo no volume de negócios tenha atingido os $13 \%$, de 54 para 47 milhões de euros. Em 2002, o valor estimado pelo Observatório foi de 39 milhões de euros, uma quebra de 17\% face a 2001.

Os baixos índices de leitura, as baixas tiragens, a ausência de visão estratégica e de marketing são razões frequentemente apontadas para justificar o desinteresse dos agentes económicos. ${ }^{30}$

Vejamos o que se passou no domínio dos incentivos institucionais, atribuídos aos media regionais através do Instituto da Comunicação Social (ICS). Nos apoios indirectos, o Estado concedeu em 2002, 13,7 milhões de euros a 571 títulos para custos de expedição postal (porte-pago). Em 2001, o mesmo incentivo totalizou 13,8 milhões, concedidos a 561 títulos; em 2000, um valor de 16,1 milhões, concedido a 717 títulos e em 1999 uma verba de 16,5 milhões, distribuídos por 668 títulos. Feitas as contas, no quadriénio em análise, o Estado atribuiu 60,1 milhões de euros, tendo-se verificado, como seria de esperar, um menor custo para o erário público a partir de 2001, o ano de mudanças legislativas.

No que se refere aos incentivos indirectos - modernização tecnológica, criação de conteúdos na Internet e iniciativa e desenvolvimento empresarial - em 2002, e só no sector da imprensa regional (sem contar com as rádios), candidataram-se 130 empresas (menos 40,9\% que em 2001) tendo sido aprovados 102 projectos e subsidiados 77 , no valor total de 1,2 milhões de euros. Já em 2001 - ano da entrada em vigor dos dois últimos incentivos -, de 220 candidaturas, foram aprovadas 138, tendo 128 beneficiado de um montante global de 1,4 milhões de euros.

\footnotetext{
${ }^{28}$ A inquietação em redor deste importante sector não é nova e mereceu, entre Abril e Junho de 1997, um conjunto de colóquios com cobertura nacional, organizados pela Alta Autoridade para a Comunicação Social, sobre "O Processo Informativo na Comunicação Social Regional e Local". O resultado da iniciativa foi reunido em livro com o mesmo título, editado pela AACS, Lisboa, em Dezembro de 97.

${ }^{29}$ Obercom, op. cit, em (16).

${ }^{30}$ Idem, Ibidem, p. 30.
} 
Um dos apoios transversais aos media, e uma das principais medidas de apoio à imprensa regional, tem a ver com a publicidade institucional por parte do Estado. De acordo com os números avançados pelo Obercom, verificou-se igualmente uma quebra. Se em 2001 este incentivo tinha conquistado uma assinalável recuperação em termos de investimento na imprensa regional (484,9 mil euros contra 215,1 mil euros em 2000), já em 2002 a queda foi brutal, passando para um investimento de 69,8 mil euros. Um ano após a entrada em vigor do novo regime de incentivos, a imprensa regional foi a que menos recebeu do conjunto dos media (televisão, imprensa nacional, rádios locais e rádios nacionais), confirmando-se, assim, que a grande fatia da publicidade institucional - distribuída através das associações do sector - é canalizada para os media de expansão nacional, em particular a televisão. ${ }^{31}$

Ao incentivo de modernização tecnológica (introduzido em 1986, tendo o Estado financiado em 16 anos, 831 projectos no valor total de 15,1 milhões de euros) foram destinados, em 2002, quase 722 mil euros para 45 projectos. No que se refere à criação de conteúdos na Internet, no mesmo ano, foram aplicados 252,7 mil euros para trinta empresas, tendo sido destinados 144,8 mil euros a dois projectos beneficiários do incentivo à iniciativa e desenvolvimento empresarial. $\mathrm{O}$ que demonstra, a partir deste último indicador, a fraca apetência do sector para as necessárias mudanças e reformas estruturais. Se por um lado, como vimos, o porte-pago é o incentivo mais desejado, porque a sua justificação é também mais simples (basta, pelos vistos, erguer a bandeira de que os jornais regionais prestam todos "serviço público" à nação), o que se destina, especificamente, a reformar empresarialmente o sector - e que surgiu de alguma forma para contrabalançar a impopularidade da redução do porte-pago - não é aproveitado. Ou seja, a medida, por mais certeira que seja em relação às necessidades do sector, não conseguiu ainda obter resultados. Esta conclusão levanta o problema se, de facto, a lógica da "empresariação" bem patente nos objectivos desta medida é ou não bem aceite pelo sector. Vejamos, simbolicamente, duas posições divergentes, socorrendo-nos das palavras de quem está dentro do sistema. António Guedes de Oliveira, director do jornal Correio de Lagos, num artigo publicado na Meios, intitulado “'Empresariar' ou adulterar a Imprensa Regional?!...”, é peremptório ao repudiar tal modelo: "É altura de dizer basta a essa tal 'empresariação' que consiste na imitação dos modelos dos grandes meios de comunicação (...). Confundir modernização e utilização das novas tecnologias com imitação de outras estruturas empresariais é desvirtuar e adulterar a própria imprensa regional. Este é apenas um atalho que conduz à sua adulteração (...)”.32

Com visão diferente, que vai ao encontro da lógica que presidiu ao novo regime, Joaquim Queirós, director do Matosinhos Hoje (jornal distinguido em 1995 com o prémio Gazeta de Imprensa Regional, pelo Clube de Jornalistas), defende, em entrevista à Meios, um sector mais inventivo. "Devemos fazer da imprensa regional uma empresa a sério, temos que ter um sentido empresarial”, disse. ${ }^{33}$

\footnotetext{
${ }^{31}$ Idem, ibidem, p. 32.

${ }^{32}$ URL: www.aind/pt/meios2002/revmarco/empresariar.html

${ }^{33}$ URL:www.aind/pt/meios2002/rev_maio/matosinhos_hoje.html
} 
Por aqui se vê que, considerando apenas um dos aspectos das políticas de comunicação para o sector, há, porventura, tantos entendimentos quantos títulos se conhecem.

Face ao exposto, a imprensa local e regional está numa encruzilhada entre a manutenção de comportamentos amadores e o desafio de se assumir profissionalmente num contexto de mercado, deixando de estar dependente da atitude paternalista e dos apoios do Estado.

\section{Perspectivando o futuro}

Consciente dos desafios, tendo em vista a estrutura-base de uma política de Comunicação Social, a AIND estabeleceu, em Fevereiro de 2002, uma plataforma negocial com os partidos políticos concorrentes às eleições legislativas (realizadas a 17 de Março, donde saiu a maioria PSD-CDS/PP) apresentando um documento com "10 Propostas para uma Política de Comunicação". No entanto, apenas um dos pontos aborda a imprensa regional e assenta, curiosamente, numa preocupação de qualificação de recursos humanos; diz respeito à definição de uma política de apoio à contratação de jornalistas generalistas, com especial incidência nas regiões do país com menor índice de desenvolvimento. ${ }^{34} \mathrm{O}$ que significa uma nova, e pertinente, preocupação: a de que não é possível ter imprensa de qualidade sem bons profissionais. E, pelas dificuldades estruturais do sector, esta é uma questão determinante para o futuro da imprensa regional.

Depois de dissertarmos sobre as políticas para o sector, no quadriénio em análise, achámos oportuno, na sequência da postura da AIND, olhar, ainda que não exaustivamente, para as propostas programáticas dos principais partidos, concorrentes às últimas legislativas, para a Comunicação Social..$^{35}$ Nomeadamente, qual o interesse que mereceu a Imprensa Regional? A constatação, após a leitura dos programas, é inequivocamente reveladora de que a televisão, ao contrário da Imprensa, ocupa o topo das preocupações. Todos, sem excepção, demonstram interesse em encontrar saídas para o serviço público de televisão. Ou não fosse este um dos principais problemas do sector em Portugal, agudizado a partir das políticas impostas de cima durante os governos de Cavaco Silva e agravado durante os seis anos de governos socialistas com a multiplicação do passivo, ${ }^{36}$ e o principal meio de atracção política, pela influência social que exerce junto das massas.

Apenas o PSD e o PCP abordam, directamente, a questão da imprensa regional. O primeiro, que viria a formar o actual Governo, considera, numa abordagem muito genérica e sem compromissos, que é preciso garantir a concorrência num quadro de economia de mercado, criando um quadro claro de apoios à imprensa regional. $\mathrm{O}$ segundo aponta, preto no branco, a reorganização dos apoios à Imprensa Regional, geridos por entidades independentes do Governo, criando condições que promovam

\footnotetext{
${ }^{34}$ URL:www.aind/pt/meios2002/rev_fevereiro/dez_propostas.html

${ }^{35}$ Referimo-nos aos programas eleitorais do Partido Social Democrata (PSD); Partido Socialista (PS); Partido Comunista Português (PCP); Partido Popular (CDS-PP) e Bloco de Esquerda (BE).

${ }^{36}$ Op. cit., em (15).
} 
as suas receitas próprias, apoiando a distribuição dos periódicos, promovendo a equidade na publicação de anúncios oficiais e as formas de cooperação no sentido da redução dos custos de produção.

Genericamente, os socialistas defendiam o aperfeiçoamento do sistema de incentivos à Comunicação Social, de forma a estimular a qualidade dos serviços prestados e a competitividade e modernização das empresas. O PP apenas refere que o sector da Comunicação Social do Estado se encontra “indisciplinado" e o Bloco de Esquerda vira as suas preocupações para a televisão, defendendo o aumento do preço do espaço publicitário de forma a sair beneficiada a imprensa, embora, tal como o PSD e PCP, indique recomendações tendo em vista um quadro normativo diferente para os apoios estatais à imprensa regional.

Que sinais têm sido dados, recentemente, que nos permitam aferir as preocupações do Governo actual sobre este sector em particular? Para lá de uma recorrente mexida na RTP, particularmente o canal aberto "A Dois”, tido como um modelo de comunicação partilhada com os cidadãos e pensada em torno da cidadania ${ }^{37}$, o que se prevê para a imprensa de proximidade?

Encontramos uma resposta em Feliciano Barreiras Duarte, secretário de Estado-adjunto do ministro da Presidência. Num artigo publicado no Expresso ${ }^{38}$, o governante dá conta, sem indicar quando, que a administração central vai apresentar um conjunto de medidas que têm por objectivo a alteração do modelo de comunicação social dominante em Portugal.

No essencial, e coincidindo com os argumentos defendidos por Arons de Carvalho para as mudanças que se operaram a partir de 2001, o actual governante sustenta que “o Estado pode e deve ter um papel regulador da imprensa regional, mas não um papel em que se substitua ao dinamismo dos empresários ou à sua capacidade de iniciativa”. E mais adianta que "um jornal que exista com a preocupação única de ter muitos exemplares suportados pelo porte-pago, só para ter anunciantes, sem cuidar de saber se é ou não lido, deve ser questionado". Ou seja, “a ajuda estatal não pode significar um prémio ao imobilismo técnico, à inércia jornalística e à deficiente gestão das empresas de comunicação social".

Considerando o actual modelo, herdado após as mudanças preconizadas pelo último governo socialista, amador e proteccionista, Feliciano Duarte anunciou o compromisso de uma nova reforma, com estímulos e regras, que consubstancie um modelo empresarial que premeie a profissionalização, o mérito e o risco. Só não diz que modelo está a ser pensado, qual a sua prioridade política. O que significa, pese embora a afirmação pública de um compromisso, que este pode ficar adiado para lá da actual legislatura.

Depreende-se desta postura oficial do actual governo, face à imprensa regional, que, no essencial, se mantêm directrizes emanadas do anterior governo, estando impli-

\footnotetext{
${ }^{37}$ Veja-se o texto de "Apresentação da nova vocação e da nova imagem do Segundo Canal de Serviço Público de Televisão", do actual ministro da Presidência, Nuno Morais Sarmento, no site do governo (www.portugal.gov.pt).

38 "Imprensa Regional: quem tem medo da mudança?" in jornal Expresso de 22 e Fevereiro de 2003.
} 
citamente reconhecido que o modelo vigente, sobretudo a redução do porte-pago, é positivo para a profissionalização do sector.

Mesmo assim, note-se a "farpa" política de Feliciano Duarte ao classificá-lo de amador e proteccionista. Este pormenor não é insignificante, porquanto ilustra o modo como os sucessivos governantes, erguidos e envolvidos em lógicas político-partidárias, gerem os dossiers. Isto é, a dificuldade em reconhecer o valor das medidas antecedentes, em adoptá-las para as melhorar.

\section{Conclusão}

O campo das políticas para o subsector da Imprensa Local e Regional demonstra, de facto, que se está perante um território movediço, onde sucessivos governos e governantes se "enterram" em medidas circunstanciais e genéricas. É a conclusão a que chegamos no quadro especificamente referenciado e analisado neste artigo. Um subsector estruturalmente débil, de conceitualização difícil, ${ }^{39}$ mas um vector estruturante no futuro das regiões.

Mais do que reclamar para si o ónus do serviço público, para justificar a dependência dos apoios estatais, esta imprensa ganha em seguir em frente pelos seus próprios pés. Insistir permanecer, sem esforço próprio, ao colo do Estado, aconchegado e fértil, não trará futuro para lá da manutenção. Pela conjuntura económica actual só restam expectativas, por um lado, face ao caminho que a imprensa regional e local vai escolher; e, por outro, se o Estado, face à necessidade de poupar, encolhe nos incentivos, mantendo uma comparticipação no profissionalismo do sector. $\mathrm{O}$ que, a acontecer, pode culminar, mais ano menos ano, numa paisagem mediática regional necessariamente mais profissional. Em suma, uma imprensa mais forte, sem perder a sua especificidade enquanto produto de informação de proximidade, ${ }^{40}$ onde os bons projectos - que os há - deixem de estar submergidos por títulos ultradependentes do Estado e sem qualidade.

Mas este desafio implica que a imprensa local e regional reforce qualitativamente a sua importante vertente sociocultural. Isto é, o seu papel de identificadora e promotora de desenvolvimento nas regiões através, sobretudo, da profissionalização da vertente informativa. Pensamos ser este o caminho para que a imprensa local e regional, tão fulcral no processo de construção da cidadania, se afirme no seu habitat e muito para lá dele.

\footnotetext{
${ }^{39}$ Com base na legislação portuguesa, o conceito de Imprensa Regional tem sido definido e redefinido ao longo da sua história. Vejamos. A lei de 1971 define-a em função de variáveis geográficas: "Imprensa Regional é constituída pelas publicações periódicas não diárias que tenham como principal objectivo divulgar os interesses de uma localidade, circunscrição administrativa ou grupos de circunscrição vizinhos". A Lei de 1975 define-a pela expansão: "as publicações periódicas podem ser de expansão nacional ou regional, considerando-se de expansão nacional as que são postas à venda na generalidade do território". A lei de 1999 já a enquadra quanto aos conteúdos: "publicações que pelo seu conteúdo e distribuição se destinem predominantemente às comunidades regionais e locais". O Estatuto de Imprensa Regional (1988), como vimos no início deste ensaio, destaca a imprensa de proximidade geográfica, dos conteúdos e a independência face aos poderes.

${ }^{40}$ Numa interessante reflexão sobre o papel da IR na actual sociedade dominada pela globalização, Paquete de Oliveira refere que estão em movimento dois fenómenos aparentemente contraditórios: por um lado, a mundialização da comunicação global e, por outro, o recrudescimento da importância do local. In "Imprensa regional à frente", $D N$ Magazine, 11 de Outubro de 2000.
} 


\section{Referências}

Alta Autoridade para a Comunicação Social, "O processo informativo na Comunicação Social Regional e Local”, Colóquios 1997, Lisboa, AACS.

Amaral, V., "Porte-pago dos jornais deve diminuir", jornal Terras da Beira, de 13 de Abril de 2000, URL: www.terrasdabeira.com

Cachada, A. A Especificidade da Imprensa Regional e os Correspondentes Locais, URL: http://inedita.com/ GabineteImprensa/cachada.htm (acesso a 2 de Fevereiro de 2004).

Cádima, F. R. (1999)Desafios dos Novos Media, Lisboa: Editorial Notícias.

Carvalho, A. A., Intervenções efectuadas na Assembleia da República, URL: www.secs.pt

Carvalho, A. A., "A Imprensa Regional tem um potencial de crescimento evidente", URL:http:// www.aind.pt/meios2000/revjaneiro/arons.html

Carvalho, A. A., Entrevista exclusiva para este ensaio, realizada via telefone a 2 de Fevereiro de 2004.

Carvalho, A. A., "Concentração na Imprensa Regional seria benéfica", URL: http://www.aind.pt/ meios2002/ver_marco/arons_carvalho.html

Duarte, F. D., "Imprensa regional: quem tem medo da mudança?”, Expresso de 22 de Fevereiro de 2003.

Estatuto da Imprensa Regional, URL: http://www.aacs.pt/lesgislacao/estatuto_da_imprensa_regional.htm (acesso a 4 de Fevereiro de 2004).

Faustino, P., "Lógicas e necessidades de apoio às empresas jornalísticas", URL: http://www.aind.pt/ meios2002/rev_maio/empresas_jornalisticas.html

Ferreira, N. H., “Associações decretam luto de quatro anos após morte da Imprensa Regional”, URL: http: //www.aind.pt/meios2000/revnovembro/luto_assoc.html

Garcia, X. L., "Repensar o jornalismo de proximidade para fixar os media locais na sociedade global”, in Revista Comunicação e Sociedade 4, Núcleo de Estudos de Comunicação e Sociedade da UM.

Imprensa, Associação Portuguesa de, (AIND) "10 Propostas para uma Política de Comunicação, URL: www.aind.pt/meios2002/ver_fevereiro/dez_propostas.html

AIND, “Programas eleitorais: A Televisão primeiro”, URL: www.aind.pt/meios2002/ver_marco/programas_ eleitorais.html

Madeira, P. M., "Imprensa nacional aposta em edições regionalizadas", in Público de 5 de Março de 2003.

Obercom (2002) Anuário de Comunicação 2002-2003, Lisboa: Obercom.

Oliveira, António Guedes, “Empresariar ou adulterar a Imprensa Regional?!”, URL: www.aind.pt/ meios2002/revmarco/empresariar.html

Oliveira, Paquete, “Imprensa regional à frente”, DN Magazine, 11 de Outubro de 2000.

Presidência do Conselho de Ministros, Decreto-Lei n. ${ }^{\circ}$ 56/20001 de 19 de Fevereiro.

Queirós, J., "Concentrar a Imprensa Regional", URL: www.aind.pt/meios2002/ver_maio/matosinhos_ hoje.html

São Vicente, Declaração, Conclusões do IV Congresso Nacional da Imprensa Regional Portuguesa, Brasil de 1 a 3 de Maio de 2000, URL: http://www.aind.pt/meios2000/revjunho/apir.html

Sarmento, N. M., "Apresentação da nova vocação e da nova imagem do Segundo Canal de Serviço Público de Televisão", URL: www.portugal. gv.pt

Sousa, H. (2000) "Políticas da comunicação: Reformas e continuidades", in Pinto, Manuel (org.), A Comunicação e os Media em Portugal (1995-1999), Braga, Departamento de Ciências da Comunicação da UM.

Traquina, N. (1999) Jornalismo: Questões, Teorias e Estórias, $2^{a}$ ed., Comunicação \& Linguagem, Lisboa: Veja.

Ribeiro, L., "Promoções na Imprensa são um "mal necessário" “ Revista Meios de Janeiro de 2002, URL:

http://www.aind.pt/meios2002/revjaneiro_2002/luis_ribeiro.html 